\section{marketing.}

Abstract: Uslovi poslovanja u kojima posluju savremena preduzeća postaju sve složeniji. Kompleksnost poslovnog okruženja uzrokovana je delovanjem kako eksternih tako i internih faktora što nameće potrebu zaokreta u upravljačkom fokusu. Jedan od ključnih zaokreta odnosi se na potrebu prilagođavanja i razvijanja novih sistema vrednovanja poslovnih performansi. Vrednovanje doprinosa marketinga poslovnim performansama je izuzetno važan, ali i složen zadatak. Sve više se u teoriji i praksi marketinga ističe potreba razvoja adekvatnih merila i sistema za vrednovanje efikasnosti marketing odluka. Bolje razumevanje marketing merila i načina na koji in menadžeri koriste su bitni faktori koji utiču na efikasnost strategijskog odlučivanja. U radu su prezentirani rezultati istraživanja načina na koji menadžeri u Srbiji percipiraju i primenjuju merila marketing performansi. Podaci koji su dobijeni terenskim istraživanjem omogućili su sagledavanje stavova menadžera o praktičnim načinima sprovođenja merenja performansi marketinga i identifikovanje merila koje menadžeri navode kao one koja najčešće koriste u poslovnoj praksi.

Ključne reči: Marketing sposobnosti, Performanse, Vrednovanje, Marketing performanse, Merila
ČLANCI/PAPERS

\section{Unapređenje sistema vrednovanja marketing performansi preduzeća}

\author{
Ljiljana Stanković, Suzana Đukić, Ana Popović
}

\section{UVOD}

Sposobnosti su kompleksan skup veština i znanja ugrađenih u organizacione procese. Kritični su izvori održive konkurentske prednosti koju koriste preduzeća da bi ostvarila superiorne performanse. Različite izvore preduzeća moguće je uspešno povezati korišćenjem superiornih sposobnosti. Marketing sposobnosti su kritične za ostvarivanje superiornih performansi preduzeća. Međutim, za razliku od vrednovanja doprinosa drugih funkcionalnih područja, malo je empirijskih istraživanja, posebno u zemljama u tranziciji, koja direktno istražuju i vrednuju uticaj marketing sposobnosti na poslovne performanse preduzeća. Opšte je poznato da su ulaganja u marketing značajna, ali da je izražen problem adekvatnog vrednovanja njihovog doprinosa poslovnom uspehu preduzeća.

Sposobnost preduzeća da marketingom kreira nove šanse u konkurentski i tehnološki sve intenzivnijem okruženju je, sve više, ključni faktor poslovnog uspeha. Ova sposobnost je ključna i prvenstveno se ogleda u proaktivnom načinu razmišljanja i delovanja i strategijskoj fleksibilnosti. Samu strategijsku fleksibilnost je moguće povećati ukoliko su strategije rezultat inovativnog reagovanja i stvaranja veće različitosti u odnosu na konkurente. Naime, u uslovima dinamičnih promena u okruženju inovativnost u svim oblastima (proizvod/usluge, procesi, organizacija, marketing, OECD, 2005) postaje ključni faktor strategija diferenciranja i pozicioniranja preduzeća. Tržišno orijentisana preduzeća su konkurentnija jer stvaraju jedinstvenu vrednost koja inkorporira elemente kreirane na osnovu jasno definisanih potreba i želja potrošača. Marketing sposobnosti su ključne za totalnu satisfakciju potrošača (Maričić, 2010), što preduzeću omogućava postizanje superiornih performansi i kreiranje i održavanje dugoročne konkurentske prednosti putem privlačenja i zadržavanja potrošača. Ti procesi su, međutim, sve složeniji, jer iako današnji potrošači imaju pred sobom veću ponudu proizvoda i usluga nego ikad, ona ne zadovoljava u potpunosti njihove sve sofisticiranije potrebe. $\mathrm{Za}$ proaktivne menadžere, takva situacija predstavlja pre šansu nego pretnju i izazov da se kreira vrednost za segmente potrošača, čije potrebe još uvek nisu zadovoljene. Menadžeri takvog opredeljenja usmeravaju sve više resursa u procese koji omogućavaju diferenciranje ponude, jer se sposobnost razvoja novih proizvoda i usluga smatra jednim od osnovnih indikatora konkurentnosti preduzeća (Stanković, Novićević, Đukić, 2011). Kreiranje i širenje znanja o tržištu postaje dominantna tema za 
menadžere, a sposobnost apsorpcije znanja sa tržišta ključna sposobnost preduzeća.

Rad je strukturiran na sledeći način: prvi deo sadrži analizu svrhe merenja marketing performansi, sledi objašnjenje potrebe kontinuiranog unapređenja sistema vrednovanja poslovnih i marketing performansi. $\mathrm{Na}$ kraju, na osnovu rezultata istraživanja teorije i prakse preduzeća u Srbiji identifikovane su percepcije i stavovi menadžera o značaju vrednovanja doprinosa marketinga, predloženi su zaključci i smernice za buduća istraživanja.

\section{SVRHA MERENJA MARKETING PERFORMANSI}

Merenje marketing performansi je jedna od ključnih aktivnosti u procesu upravljanja savremenih preduzeća. Racionalnost merenja uslovljena je, pre svega, jasno definasom svrhom i izborom sistema merila koji će omogućiti da se ostvare postavljeni ciljevi. Jedna od ključnih svrha merenja poslovnih i marketing performansi je kontrola. To je faza procesa upravljanja u kojoj se meri ostvarenje ciljeva, strategija i efikasnost organizacije i preduzimaju korektivne akcije kada se ustanovi da je to neophodno (Milisavljević, 2010). Merenje marketing performansi pomaže menadžmentu da kontinuirano preispituje svoj poslovni model, da kreira vrednost za ključne subjekte i grupe. Ono je, takođe, važno sredstvo komunikacije i implementiranja strategije. Na primer, merenjem brzine odgovora na porudžbine kupca menadžment želi da istakne koliko je to važno. Logično je da se od zaposlenih očekuje da teže da ispune ove ciljeve ili da poboljšaju brzinu odgovora. U procesu vrednovanja marketing performansi neophodno je koristiti holistički pristup koji podrazumeva razvijanje i primenu odgovarajućeg uravnoteženog sistema merenja koji podržava ne samo marketing, već i strategijske namere organizacije. Dobro postavljen sistem mera performansi upućuje jasne signale svim zaposlenima o prioritetima u poslovanju jedne organizacije. Vrednovanje efekata marketing aktivnosti je veoma značajno za svaku organizaciju, ne samo zbog kontrole upotrebe resursa i sposobnosti, već i kao osnove za motivisanje, nagrađivanje zaposlenih i potrebe unapređenja konkurentske pozicije.

Uopšteno, merenje može biti smatrano načinom da se pripiše kvantitativna vrednost određenom (objektivnom ili subjektivnom) atributu ili rezultatu. Kako bi se na pravi način merile akcije i performanse, kriterijumi atributa koji treba da se razmatraju moraju biti definisani (Lages et al., 2008; Patterson, 2009; Seggie et al., 2007 ). Kada je reč o vrednovanju rezultata marketinga, u pitanju je veoma kompleksan proces, jer marketing aktivnosti često imaju subjektivne efekte i uključuju delovanje brojnih faktora (Llonch, Eusebio, \& Ambler, 2002; Petersen i ostali, 2009; Seggie i ostali, 2007). Složenost vrednovanja se povećava i zbog problema fluktuacije vrednosti prilikom merenja povraćaja vezanih za marketing odluke i/ili aktivnosti (Rust i ostali, 2000). Menadžeri često ne mogu pouzdano da odrede finansijske prinose na ulaganja $u$ marketing (Petersen i ostali, 2009; O Sullivan, Abela, 2007)). $S$ obzirom na to da ulaganja u marketing uključuju brojne aktivnosti na različitim nivoima (od funkcionalnog do korporativnog) i utiču na uspeh realizacije ne samo marketing, već poslovnih strategija, razumevanje povraćaja na ulaganja u marketing je komplikovano. Menadžeri se često suočavaju sa problemom da pomire suprotstavljene ciljeve: opravdaju ulaganja, odbrane predložene strategije i adekvatno vrednuju prethodne i buduće troškove i rezultate (Clark, 1999; Ambler, 2000; Ambler i ostali, 2004;Seggie i ostali, 2007; Gonzales \& Gonzales, 2005; Gupta i ostali, 2004, Doyle, 2007). Razvoj pouzdanog i primenljivog sistema vrednovanja marketing performansi postaje važan cilj za podršku odlučivanju i definisanje budžeta za marketing aktivnosti (Ling, 2011), s obzirom na značajan, pre svega, tržišni rizik ulaganja u marketing (Hooley i ostali, 2005; Rust o ostali, 2004). Izbor i korišćenje adekvatnih merila doprinosi racionalnijoj alokaciji resursa (Lovett \& MacDonald, 2005; Gupta, rego, 2005; Gupta, Zeithami, 2006Hoffman i ostali, 2011, Rust i ostali, 2004; laRocca i ostali, 2012, Farris i ostali, 2006, Daviss, 2005) što, posledično, smanjuje i rizik ulaganja i doprinosi unapređenju konkurentnosti.

Potreba vrednovanja marketing aktivnosti nije sporna i postoji opšta saglasnost u literaturi o neophodnosti adekvatnog vrednovanja doprinosa marketinga poslovnim performansama preduzeća. Međutim, na osnovu pregleda relevantnih izvora može se zaključiti da ne postoje jasni zaključci o tome koja merila treba koristiti i kako ih primeniti. Brojna istraživanja su bila usmerena na nekoliko dimenzija vrednovanja, naročito na one povezane sa procenom marketing performansi ${ }^{1}$. Analize prethodno realizovanih istraživanja pokazuju da je mnogo više studija realizovano u razvijenim privredama na primerima kompanija koje su tržišno orijentisane. Takođe, rezultati

U pregledu literature navedeni su neki od radova u kojima su prezentirani rezultati istraživanja koje su autori analizirali. 
istraživanja pokazuju da se vrednovanje marketinga i izbor sistema merila razlikuje u zavisnosti od kultura u kojima se realizuju poslovne i marketing aktivnosti. Relativno je malo istraživanja koja su realizovana u drugim zemljama i kulturama, posebno u zemljama u tranziciji i tržištima u razvoju.

Polazeći od stepena razvoja marketing prakse u zemljama u tranziciji, logično je očekivati da je problem vrednovanja ulaganja u marketing još izraženiji u odnosu na druge privrede. Polazeći od tog saznanja realizovano je istraživanje prakse preduzeća u Srbiji. Osnovni cilj istraživanja je prikupljanje informacija o tome kako menadžeri pristupaju vrednovanju doprinosa marketinga poslovnim performansama preduzeća u Srbiji i koja merila najčešće koriste u tom procesu. Rezultati istraživanja su osnova za sticanje novih znanja o merenju rezultata aktivnosti marketinga i doprinos razumevanju sistema vrednovanja $\mathrm{u}$ poslovnoj praksi preduzeća u Srbiji.

U istraživanju koje je realizovano na prigodnom uzorku autori su se fokusirali na identifikovanje stavova menadžera i marketing merila koja oni smatraju relevantnim i primenljivim u praksi. Dobijeni rezultati upoređeni su sa relevantnim rezultatima sličnih istraživanja koja su realizovana u različitim zemljama i kulturama.

$\mathrm{Na}$ izbor sistema vrednovanja marketing performansi, i pojedinih merila u okviru odredjenih grupa, utiču brojni faktori. Razumljivost je jedan od zahteva jer se može primeniti mera koja je razumljiva. Ona je usko povezana sa jednostavnošću. Kompleksna merila nisu uvek dovoljno jasna njihovim korisnicima što može uticati na odbacivanje te mere ili na pogrešno reagovanje u procesu obavljanja poslovnih aktivnosti. Limitirajući faktor izbora seta merila je mogućnost njihovog kvantitatvnog izražavanja. Ključna pretpostavka uspešne primene odgovarajućeg merila je njegova usaglašenost sa sistemom vrednovanja poslovnih performansi preduzeća kao celine, ali i nižih nivoa odlučivanja. To je pouzdana osnova za prikupljanje adekvatnih informacija na osnovu kojih je moguće proceniti koje aktivnosti marketinga, kao i drugih funkcionalnih područja, dodaju vrednost, odnosno na kojim aktivnostima se gubi vrednost. Izbor mere marketing performansi mora da omogući da se izbegne proizvoljnost tumačenja. Pogodnost za modifikovanje i unapređenje je jedna od važnih karakteristika mera performansi. Potencijalni broj merila marketing performansi je veliki. Veliki broj korišćenih merila može da zbuni menadžere i zaposlene što nameće potrebu izbora optimalnog broja. Efikasno merenje marketing performanisi omogućava dobija- nje blagovremene povratne informacije. S obzirom da je jedna od osnovnih svrha merenja efikasnije korišćenje resursa i adekvatno konkurentsko pozicioniranje, za to je potreban kontinuirani protok informacija. Brze povratne informacije su pretpostavka uspešnog prevazilaženja nastalih problema.

\section{POTREBA KONTINUIRANOG UNAPREDJENJA VREDNOVANJA MARKETING PERFORMANSI}

Karakteristika uspešnih, marketing orijentisanih preduzeća je njihova orijentacija ka stvaranju novih tržišta ili redefinisanje poslovanja kako bi svoju konkurenciju učinili inferiornom ili zanemarljivom. To je kompleksan proces i zahteva nevidljive veze izmedju svih procesa i funkcija, posebne veštine i učenje što značajno smanjuje mogućnost kopiranja. Davno je još P. Draker isticao da su efikasan marketing i inovacije provereni načini da kompanije stiču održivu konkurentsku prednost. Zahtevi za inovacijama i odgovarajućom marketing orijentacijom još su izraženiji u uslovima globalne konkurencije. Najbolje kompanije efikasno upravljaju tržištem realizacijom marketing i poslovnih strategija kojima se kreira superiorna vrednost za sve učesnike $\mathrm{u}$ lancu vrednosti.

Intenzivne promene uslova poslovanja kaarakteristične za kraj prethodnog i početak novog veka, menjaju odnose na tržištu i zahtevaju redefinisanje uloge marketinga, samim tim i sposobnost organizacije da meri njegov doprinos. Osnove za sticanje konkurentske prednosti nisu više samo superiorni izvori, već i superiorne sposobnosti. Povezivanje i saradnja između učesnika na tržištu zahteva, sve više, fokusiranje menadžmenta na kreiranje dugoročnih odnosa ne samo sa potrošačima, već i sa ostalim stejkholderima.

Adekvatni sistemi merenja marketing performansi su siguran putokaz menadžmentu preduzeća. Naime, informacije koje proizilaze iz rezultata merenja pokazuju koju vrstu promena treba inicirati, kada i na kojim nivoima. Na osnovu rezultata dobijenih merenjem preduzeće saznaje kakva je njegova konkurentska pozicija, spoznaje koliko i kako može poboljšati svoj položaj ukoliko realizuje neophodne promene, bilo radikalne ili/i inkrementalne.

Poslednjih decenija sve je više autora iz oblasti marketinga koji nastoje da teorijski uobliče, a empirijskim istraživanjima provere, odgovarajuće sisteme vrednovanja. Opšte je prihvaćen stav da je oslanjanje na tradicionalne sisteme merenja marketing performansi, koja se odnose prevashodno na preduzeće 
kao celinu, nedovoljno jer ne pruža potrebne informacije za efikasno upravljanje ne samo marketing, već i ukupnim resursima i sposobnostima preduzeća. Veoma je teško adekvatno vrednovanje doprinosa marketinga. Naime, značajan deo aktive koja nastaje kao rezultat delovanja marketinga je nematerijalnog karaktera (vrednost marke, imidža i reputacije, relaciona aktiva i dr.) za čije vrednovanje nije dovoljno korišćenje samo agregatnih i finansijskih merila.

Imajući u vidu značaj marketinga za konkurentsko pozicioniranje preduzeća, potreba razvijanja i kontinuiranog unapređenja sistema merila je trajan zadatak menadžmenta. Doprinos marketinga poslovnom uspehu preduzeća nije uvek moguće pouzdano izmeriti jer on prožima različita funkcionalna područja i procese, a za uspeh u realizaciji marketing odluka bitno je ponašanje ne samo internih, već i eksternih stjkholdera. Neophodnost da se izmeri prinos koji generišu ulaganja u marketing uslovila je potrebu razvijanja sistema merila koji omogućava vrednovanje ne samo materijalne, već i nematerijalne imovine preduzeća. Budući da u strukturi ukupne imovine raste učešće nematerijalne, i da se konkurentska prednost sve više stiče po osnovu ove imovine neprekidno se traga za konzistentnim sistemima merenja (Janošević, Dženopšoljac, 2011; Krstić, Sekulić, 2007).

Tradicionalni pristupi merenja poslovnih performansi su uglavnom jednodimenzionalni, fokusirani na finansijska merila, orijentisani na kratkoročne ciljeve, statitični, neprilagođeni specifičnim potrebama preduzeća. Proaktivno reagovanje preduzeća na promene u okruženju uslovilo je potrebu inovacija u različitim oblastima i fazama upravljanja. Evidentne su veoma značajne promene u oblasti vrednovanja i merenja poslovnih performansi. Tradicionalni fokus zamenjen je uravnoteženim pristupom i primenom, najpre dvodimenzionalnih, a zatim i multidimenzionalnih modela koji imaju dijagnostički karakter jer sadrže mehanizme za identifikovanje uzročno posledičnih odnosa. Razvijeni su strategijski sistemi merenja čijom primenom je moguće objasniti promene u internom i eksternom okruženju.

Analizom referentne literature ${ }^{2}$ može se zaključiti da nema univerzalnih i najboljih sistema za vrednovanje poslovnih performansi. Moguće je definisati konceptualni okvir koji se može prilagođavati u zavisnosti od:

\footnotetext{
Analiziran je veliki broj publikovanih radova u kojima su razmatrana pitanja vrednovanja poslovnih performansi, kao i performansi marketinga. Izvori koji su cesto citirani, navedeni su u literature.
}

- Potrebe i svrhe merenja u svakom konkretnom preduzeću;

- Nivoa analize (funkcionalno područje, proces, poslovna jedinica, preduzeće kao celina);

- Izabranih kriterijuma i pouzdanosti merila (evolucija i sposobnost prilagođavanja potrebama organizacije);

- Vremenske dimenzije (kratak i dugi rok);

- Mogućnost uopštavanja i upoređivanja sa drugim organizacijama i kulturama.

Osnovne karakteristike strategijskih sistema merenja performansi su: usklađenost sa ciljevima i strategijama, povezanost operativnih i strategijskih ciljeva, višedimenzionalnost merenja, izbor merila u okviru svake dimenzije u zavisnosti od ciljeva, identifikovanje uzročno-posledičnih odnosa unutar i između različitih perspektivi merenja (Gimbert et all: 2010, 477-497).

Izabrani model vrednovanja performansi marketinga trebalo bi da doprinosi kontinuiranom strategijskom unapređenju. U skladu sa izabranim prioritetnim ciljevima proces kontinuiranog strategijskog unapređenja podrazumeva stalno preispitivanje identifikovanih merila performansi. Potrebno je definisati merila za izabrane strategijske ciljeve. Proces kontinuiranog strategijskog unapređenja osigurava fleksibilnost sistema.

$\mathrm{Na}$ osnovu rezultata teorijskih istraživanja brojnih modela koji su koncipirani za potrebe merenja, pre svega poslovnih performansi preduzeća, može se zaključiti da je za vrednovanje marketing performansi poželjno koristiti različite modele što je uslovljeno ciljevima vrednovanja i nivoom odlučivanja. Naime, u određenim slučajevima opravdano je koristiti jednodimenzionalne modele (modeli rezultata) jer oni objašnjavaju uticaj konkretne varijable na krajnji rezultat, na primer, uticaj stope zadržavanja potrošača na finansijske performanse preduzeća. Česta je potreba da se u procesu vrednovanja koriste dvodimenzionalni modeli koji se prevashodno zasnivaju na portfolio analizi. Korišćenjem dvodimenzionalnih modela moguće je objasniti uticaj dve dimenzije na rezultat. $\mathrm{Na}$ primer, poželjno je vrednovati uticaj profitabilnosti i lojalnosti potrošača na finansijski rezultat preduzeća.

Za vrednovanje ukupnog doprinosa marketinga poslovnim performansama preduzeća, posebno na strategijskom nivou, poželjno je koristiti multidimenzionalne modele jer njihova primena obezbedjuje kritične informacije koje su neophodne menadžerima za donošenje strategijskih odluka. Poslednjih nekoliko decenija intenzivno se traga za razvijanjem modela za 
vrednovanje koji su usaglašeni sa novim poslovnim modelima i doprinose operacionalizaciji marketing (i ostalih funkcionalnih strategija) i poslovne strategije sa definisanim ciljevima, vizijom i misijom preduzeća (Kaplan i Norton, 1996; Javorski, Stankovic, 2002; Milisavljević, 2010, i dr.). Preovlađujuća shvatanja su da multidimenzionalni modeli koji polaze od više dimenzija ili perspektiva i koriste različiti broj merila predstavljaju pouzdanu osnovu za vrednovanje doprinosa različitih poslovnih funkcija i obezbeđuju relevantne informacije za strategijsko odlučivanje. Kao i za druga funkcionalna područja, i za vrednovanje doprinosa marketinga potrebno je u okviru svake dimenzije izabrati nekoliko specifičnih merila kojima se vrednuje njegov doprinos. Efekti marketinga su višestruki i neophodno ih je analizirati ne samo u okviru grupe koja sadrži merila koja su povezana sa potrošačima, već i ostalim merilima kojima se objašnjava uspešnost procesa, učenja i rasta, kao i međuzavisnost sa finansijskim uspehom. Broj merila je različit i u zavisnosti od specifičnih potreba i svrhe merenja moguće je izabrati njihovu optimalnu kombinaciju.

Izabrani sistem merila trebalo bi da omogući ( $\mathrm{Ra}-$ yport, Javorski, 2001):

- Definisanje marketing strategije i njenu uravnoteženost sa poslovnom strategijom, kao i njeno prevođenje u željene rezultate;

- Identifikovanje specifičnih merila koja odražavaju željene rezultate;

- Izbor vodećih i pratećih indikatora i njihovo međusobno usklađivanje i povezivanje. Na primer, finansijska merila (\% prihoda po osnovu osvajanja novih kupaca, smanjivanje troškova kao rezultat lojalnosti potrošača i sl) kao prateće indikatore marketing, ali i poslovnih, performansi trebalo bi jasno povezati sa vodećim indikatorima (lansiranje novog proizvoda na tržište, inovacije poslovnog modela, povezivanje sa potrošačima i sl.) i utvrditi smer i intenzitet uticaja;

- Izbor standarda za upoređivanje (ciljne veličine) ostvarenih rezultata i utvrđivanje odstupanja u odnosu na postavljene ciljeve.

\section{METODOLOGIJA ISTRAŽIVANJA}

Razvoj i testiranje upitnika - Predmet istraživanja u ovom radu su percepcije i stavovi menadžera (top menadžeri, marketing menadžeri i menadžeri finansija) vezani za merila marketing performansi i načini njihove primene u preduzećima koje vode ti menadžeri.
Prevashodno su korišćena kvalitativna istraživanja, pre svega, zbog činjenice da je reč o preliminarnom, početnom istraživanju ove teme u praksi preduzeća u Srbiji. Cilj istraživanja je prikupljanje informacija na osnovu kojih je moguće identifikovati i razumeti načine na koje menadžeri u Srbiji percipiraju i koriste marketing merila identifikovana u relevantnoj literaturi iz oblasti menadžmenta i marketinga. Za realizaciju postavljenog cilja razvijen je podsetnik za vođenje intervjua koji je fokusiran na nekoliko ključnih tema:

- opšti stavovi menadžera o značaju vrednovanja prinosa na ulaganja u marketing aktivnosti i njihovo znanje o marketing merilima,

- da li se u njihovim preduzećima vrednuju ulaganja u marketing aktivnosti,

- koja merila menadžeri koriste u praksi za vrednovanje doprinosa marketing aktivnosti ukupnim poslovnim performansama,

- nivo kompleksnosti konkretnih merila koja se upotrebljavaju (najteže i najlakše za primenu).

U okviru realizacije prve dve teme prikupljenje su informacije koje se odnose na mišljenje menadžera i praksu preduzeća vezanu za ulaganja u marketing i njihovu kontrolu. Druge dve omogućavaju da se analiziraju konkretna merila. Finalni podsetnik za vođenje intervjua je testiran od strane 2 eksperta i 10 menadžera iz srednjih i velikih preduzeća koja posluju na poslovnom tržištu. U finalnom upitniku su predložena merila do kojih se došlo istraživanjem literature i na osnovu podataka dobijenih ovim intervjuima.

Za izbor marketing merila koja su uključena $u$ istraživanje korišćeno je nekoliko kriterijuma:

- učestalost pominjanja određenog merila u relevantnoj literature,

- merila koja su 2 ili više puta navedena u intervjuima sa menadžerima,

- uopštavanje i grupisanje merila, gde god je to bilo moguće (polazna osnova za uopštavanje i grupisanje merila bile su dimenzije merenja definisane u najčešće korišćenim multidimenzionalnim modelima, dopunjeni specifičnim merilima koje se odnose na pojedine marketing aktivnosti).

Finalna verzija upitnika sastoji se od 38 merila. Izabrana merila su pogodna za merenje ukupnih poslovnih performansi, kao i za merenje doprinosa marketinga poslovnom uspehu preduzeća. Od ispitanika je traženo da označe stepen svoje upoznatosti sa svakim od njih (da/ne, dihotomna pitanja), koliko često ih koriste (5-ostepena Likertova skala, $1=$ jednom godišnje, a $5=$ svakodnevno), i nivo značaja (5-ostepena 
Likertova skala, 1=uopšte nije bitno, a 5=veoma je bitno). Lista ponuđenih merila prezentirana je u narednom pregledu.

Adekvatnost upitnika je testirana na osnovu mišljenja i stavova eksperata na osnovu kojih su izvršene određene korekcije. Takođe, na osnovu stavova menadžera izvršeno je pred testiranje koje je poslužilo kao osnova za dokazivanje sveobuhvatnosti i konzistentnosti u interpretiranju rezultata.

Pregled BRoJ 1. Merila marketing i poslovnih performansi

\begin{tabular}{|c|c|}
\hline & I. ODNOSI PREMA KLIJENTIMA \\
\hline 1. & Stepen zadovoljstva kupaca proizvodom/uslugom \\
\hline 2. & Sposobnost proizvoda/usluge da reši probleme kupcima \\
\hline 3. & Broj ideja pristiglih od kupaca \\
\hline 4. & Porast broja porudžbina ključnih kupaca \\
\hline 5. & Povećanje broja novih kupaca \\
\hline 6. & Broj poseta kupcima \\
\hline 7. & Vreme trajanja odnosa sa kupcem (poznavanje kupaca) \\
\hline 8. & Troškovi opsluživanja pojedinačnih kupaca \\
\hline 9. & Lojalnost kupaca (broj ponovljenih porudžbina) \\
\hline 10. & Broj reklamacija \\
\hline 11. & Broj izgubljenih kupaca \\
\hline 12. & Promena tržišnog učešća \\
\hline 13. & Profitabilnost kupaca \\
\hline \multirow[t]{2}{*}{14.} & Životna vrednost kupaca \\
\hline & II UNUTRAŠNJI PROCESI \\
\hline 15. & Broj novih proizvoda/usluga uvedenih u prethodnoj godini \\
\hline 16. & Vreme potrebno za izradu novog proizvoda/usluge \\
\hline 17. & Vreme potrebno za lansiranje novog proizvoda/usluge na tržište \\
\hline 18. & Vreme potrebno da se ostvari profit od novog proizvoda/usluge \\
\hline 19. & Brzina odgovora na zahteve kupaca \\
\hline \multirow[t]{2}{*}{20.} & Prosečno vreme reagovanja preduzeća na određenu poslovnu mogućnost u okruženju \\
\hline & III UČENJE I RAZVOJ ZAPOSLENIH \\
\hline 21. & Raspoloživo znanje zaposlenih o tržištu \\
\hline 22. & Broj predloga, ideja koje plasiraju zaposleni \\
\hline 23. & Broj sati koje zaposleni provedu u realizaciji kreativnih aktivnosti marketinga \\
\hline 24. & Broj sati koje zaposleni na poslovima marketinga koriste za učenje i sticanje novih znanja \\
\hline 25. & Broj sati koje zaposleni provedu na usavršavanju postojećeg znanja \\
\hline 26. & Broj seminara, kurseva, treninga obuke koje su dostupni zaposlenima \\
\hline 27. & Stepen zadovoljstva zaposlenih \\
\hline \multirow[t]{2}{*}{28.} & Produktivnost zaposlenih \\
\hline & IV FINANSIJE \\
\hline 29. & Stopa rasta prihoda \\
\hline 30. & Stopa prinosa na uložena sredstva \\
\hline 31. & Stopa prinosa na uložena sredstva u obavljanje marketing aktivnosti \\
\hline 32. & Procenat prihoda od novih proizvoda/usluga \\
\hline 33. & Stopa povraćaja ulaganja u razvoj novih proizvoda/usluga \\
\hline 34. & Vreme povraćaja uloženih sredstava u razvoj novih proizvoda/usluga \\
\hline 35. & Procenat ušteda od razvoja novih proizvoda/usluga \\
\hline 36. & Procenat prihoda od novih kupaca \\
\hline 37. & Smanjenje troškova po osnovu prodaje novih proizvoda/usluga postojećim kupcima \\
\hline
\end{tabular}


Profil uzorka i način prikupljanja podataka - Istraživanjem su obuhvaćena preduzeća koja posluju na poslovnom tržištu iz različitih sektora i grana u republici Srbiji. Anketirani su top menadžeri, menadžeri marketing i finansijske funkcije. Najveći broj anketiranih su visokoobrazovani kadrovi. Anketiranje su realizovali autori rada, korišćenjem direktnog intervjua. Istraživanjem je obuhvaćeno 50 preduzeća. U izboru preduzeća korišćen je namerni uzorak, uzorak stručnjaka. Za nameran izbor preduzeća autori su se opredelili polazeći, pre svega, od saznanja da se u preduzećima u Srbiji nedovoljno koriste strategijski sistemi za vrednovanje poslovnih performansi i da relativno mali broj preduzeća razvija tržišnu orijentaciju i vrednuje doprinos marketinga poslovnom uspehu. Preduzeća su izabrana polazeći od sledećih kriterijuma: veličina preduzeća (srednje i veliko), poslovni uspeh (da ostvaruje poslovni dobitak) orijentisanost na međunarodno tržište i da posluje najmanje 10 godina na poslovnom tržištu. Pretpostavka je da će ispitanici na osnovu dugogodišnjeg znanja i iskustva svojim odgovorima doprineti da se definišu osnove za buduća reprezentativna istraživanja.

\section{ANALIZA PODATAKA I REZULTATA ISTRAŽIVANJA}

Korišćena je dvofazna analiza podataka. U prvoj fazi, analizirana su predložena merila performansi, upoznatost menadžera, stavovi menadžera o relevantnosti pojedinih merila i frekvencija korišćenja. U drugoj fazi, polazeći od rezultata prethodnih istraživanja prezentiranih u relevantnoj literaturi, autori su se fokusirali na 12 najvažnijih merila. Naime, pošlo se od pretpostavke da menadžeri koriste set merila (a ne jedno), najčešće od 3 do 6 u svakoj perspektivi. Ovo mišljenje potvrđeno je i u predtestiranju kada su ispitanici sugerisali da teže da ne koriste više od 10 merila za upravljanje poslovanjem. Za ovih 12 merila, primenili smo eksploratornu faktorsku analizu (EFA) da bismo utvrdili da li je grupisanje koje je najpre urađeno na osnovu pregleda literature tokom faze predtestiranja, odgovarajuće. Uz to smo i izračunali merilo interne konzistentnosti, Kronbahov alfa koeficijent (Cronbach's alpha), za faktore koji slede iz EFA. Potom smo koristili proceduru totalne agregacije da bismo procenili model višeg reda i testirali značaj određenih dimenzija marketing merila koja koriste preduzeća u Srbiji.

Istraživanjem je utvređno da su menadžeri upoznati sa predloženim merilima i da u svojoj praksi koriste više komplementarnih indikatora (umesto oslanjanja na samo 1) kako bi se što bolje razumelo stanje u konkretnom preduzeću. To je pristup koji ima odgovaraću potporu u relevantnoj literaturi i praksi uspešnih preduzeća. Najpoznatija su merila iz grupe finansijskih, a najpoznatije pojedinačno merilo je stopa rasta prihoda (svi anketirani menadžeri su upoznati sa tim merilom). Bitno je istaći i da je najveći broj menadžera označio satisfakciju potrošača kao veoma bitno merilo (ocena 4,85). Međutim, kako su mnoga merila vezana za satisfakciju izuzetno subjektivna, potrebna je kritička interpretacija. Po ugledu na prethodna istraživanja, ispitivali smo moguću korelaciju između procenjenog nivoa značaja merila i frekvencije njegove primene. Za većinu merila nije pronađena značajna korelacija, a kod nekih je čak identifikovan nesklad između nivoa značaja i frekventnosti korišćenja. Ovakvi rezultati nisu specifični samo za preduzeća u Srbiji. Pregledom literature moguće je zaključiti da ima sličnih rezultata i u praksi preduzeća iz razvijenih zemalja tržišne privrede. Kvalitativnim istraživanjima je otkriveno da većina anketiranih menadžera teži da visoko rangira varijable na skali značajnosti, ali da prema najvišem nivou procenjene frekvencije upotrebe, rezultati znatno variraju. Rezultati istraživanja pokazuju da merila koja se najčešće koriste nisu procenjena kao najznačajnija. Razlog njihove učestale primene je jednostavnost merenja. Sa druge strane, postoje i ona merila koja su procenjena kao veoma značajna, ali se retko koriste, na primer, troškovi opsluživanja pojedinih kupaca. Nizak značaj i niska frekvencija upotrebe karakterišu neka merila (stopa povraćaja ulaganja u razvoj novih proizvoda/usluga, procenat ušteda od razvoja novih proizvoda /usluga, promena tržišnog učešća) koja su teška za vrednovanje. Bitno je istaći da je finansijsko merilo stopa rasta prihoda među najčešće korišćenim.

Uz to su sprovedeni i t-test i hi-kvadrat test za otkrivanje različitih grupa ispitanika i nivoa značaja, upoznatosti i korišćenja merila. Interesantni su nalazi da su značajnije razlike procenjenog nivoa značajnosti pojedinih merila utvrđene u okviru grupe odnosi prema klijentima $\mathrm{u}$ odnosu na ostale grupe merila. $\mathrm{Na}$ primer, otkrivena je značajna razlika $(\mathrm{t}=2,785 \mathrm{i}$ $\mathrm{p}<0,01$ ) kod procenjenog nivoa značaja lojalnost kupaca koja je mnogo bitnija marketing menadžerima $\mathrm{u}$ velikim preduzećima u odnosu na preduzeća srednje veličine. Takođe, evidentne su razlike o značajnosti ovog merila marketing menadžerima u odnosu na top menadžere i menadžere finansija.

Porast broja porudžbina ključnih kupaca bitni su svim preduzećima što je u skladu sa shvatanjem da 
Pregled BRoJ 2. Ocena značaja merila i frekvencija korišćenja

\begin{tabular}{|c|c|c|}
\hline I . ODNOSI PREMA KLIJENTIMA & Značaj merila & Frekvencija korišćenja \\
\hline Porast broja porudžbina ključnih kupaca & 4,85 & 3,95 \\
\hline Vreme trajanja odnosa sa kupcem (poznavanje kupaca) & 4,82 & 3,83 \\
\hline Lojalnost kupaca (broj ponovljenih porudžbina) & 4,95 & 3,89 \\
\hline \multicolumn{3}{|l|}{ II UNUTRAŠNJI PROCESI } \\
\hline Broj novih proizvoda/usluga uvedenih u prethodnoj godini & 4,78 & 3,01 \\
\hline Vreme potrebno za lansiranje novog proizvoda/usluge na tržište & 4,81 & 3,05 \\
\hline Brzina odgovora na zahteve kupaca & 4,79 & 3,19 \\
\hline \multicolumn{3}{|l|}{ III UČENJE I RAZVOJ ZAPOSLENIH } \\
\hline Broj sati koje zaposleni provedu na usavršavanju postojećeg znanja & 4,68 & 3,01 \\
\hline Stepen zadovoljstva zaposlenih & 4,90 & 3,03 \\
\hline Produktivnost zaposlenih & 4,67 & 3,15 \\
\hline \multicolumn{3}{|l|}{ IV FINANSIJE } \\
\hline Stopa rasta prihoda & 5,00 & 4,95 \\
\hline Stopa prinosa na uložena sredstva & 4,55 & 4,05 \\
\hline Procenat prihoda od prodaje novim & 4,33 & 3,04 \\
\hline
\end{tabular}

zadržavanje potrošača i razvijanje dugoročnih odnosa sa ključnim kupcima doprinosi unapređenju ne samo marketing, već i poslovnih performansi preduzeća. Iako nije statistički značajna, postoji razlika u rangiranju merila od strane menadžera proizvodnih u odnosu na preduzeća iz oblasti usluga. Za menadžere proizvodnih preduzeća veoma su značajna merila sposobnost novog proizvoda reši problem kupca, broj ideja pristiglih od kupaca vreme trajanja odnosa sa kupcem, broj reklamacija, stopa povraćaja ulaganja u razvoj novih proizvoda. Menadžeri preduzeća iz oblasti usluga kao naznačajnije navode lojalnost kupaca, troškove opsluživanja pojedinih kupaca, broj izgubljenih kupaca, stopu rasta prihoda.

Najznačajnija merila - Analiza rezultata istraživanja pokazuje da postoje značajne razlike u oceni značaja pojedinih merila za vrednovanje doprinosa marketinga poslovnom uspehu preduzeća i frekvencije njihovo korišćenja. Iako su pojedina merila vrednovana kao veoma značajna (prosečna ocena iznad 4) u praksi se ta ista merila nedovoljno koriste. $U$ pregledu broj 2 prikazana su po tri merila iz svake grupe koje su menadžeri ocenili kao veoma značajna. Podaci o frekvenciji njhovog korišćenja pokazuju da, iako su značajna, još uvek se nedovoljno koriste u praksi preduzeća u Srbiji za unapređenje poslovnih performansi.

\section{IMPLIKACIJE ZA MENADŽERE, OGRANIČENJA I PRAVCI DALJEG ISTRAŽIVANJA}

Kao što je već u prethodnom delu rada istaknuto, poslednjih godina se sve veća pažnja poklanja vrednovanju poslovnih performansi preduzeća i razvijanju adekvatnih sistema merenja. U okviru tih sistema značajno mesto zauzimaju marketing merila. Sa razvojem strategijskog marketinga, vrednovanje doprinosa marketinga dobija na značaju. I dalje je bitno da se pouzdano procenjuje doprinos svakog instrumenata marketinga kako bi se opravdala ulaganja u određenu kombinaciju instrumenata marketinga koji čine konkretnu ponudu preduzeća. Međutim, značajna sredstva preduzeća ulažu i za obavljanje strategijskih marketing aktivnosti čiji doprinos je moguće adekvatno vrednovati ukoliko se primeni holistički pristup i adekvatno analizira značaj i doprinos svake determinante holističkog marketinga uspehu preduzeća kao celine.

Analiza relevantne literature iz oblasti marketinga i menadžemeta, primera najbolje prakse i rezultati ovog istraživanja, pokazuju da ne postoji univerzalno merilo za vrednovanje doprinosa svih, pa i marketing aktivnosti. S obzrom na interese različitih stejkholdera i potrebe odgovarajućeg strategijskog reagovanja, poželjno je razvijati strategijske sisteme vrednovanja i koristiti određena merila koja, u zavisnosti od definisanih strategijskih i operativnih ciljeva preduzeća, omogućavaju ne samo adekvatnu kontrolu, već i mo- 
tivisanje i nagrađivanje zaposlenih, što u konačnom doprinosi unapređenju poslovnih performansi preduzeća.

$\mathrm{Na}$ osnovu rezultata istraživanja moguće je predložiti nekoliko implikacija za menadžere:

Potrebno je razvijati i koristiti merila kojima se može ocenjivati ne samo pojedinični doprinos određene aktivnosti, već pre svega, kako se to odražava na ukupan rezultat preduzeća i njegovu strategijsku poziciju. Na primer, dužina trajanja odnosa sa kupcem i njegovo zadržavanje su veoma značajni. Međutim, neophodno je stalno preispitivati koliko je opravdano zadržavanje kupaca i kako se ono odražava na finansijske performanse preduzeća u dugom roku. Istraživanja su pokazala da su performanse marketinga višedimenzionalni konstrukt, zbog čega menadžeri moraju uzeti u obzir brojne ne/finansijske indikatore i uskladiti ih sa ciljevima ostalih poslovnih funkcija i preduzeća kao celine. Takođe, veoma je bitna ocena njihovog značaja kako u kratkom tako i u dugom roku. Merila moraju biti orijentisana ka ciljevima i pružati informacije neophodne za donošenje operativnih i strategijskih marketing i poslovnih odluka. Multidimenzionalnost marketing merila i viši nivo njihove agregacije ukazuje na mogućnost njihovog kombinovanja i dekomponovanja za specifične svrhe. Marketing merila mogu služiti i kao inputi opštih merila performansi kompanije. Isto tako, svako pojedinačno merilo može obezbediti različite nivoe informacija u zavisnosti od svrhe analize. Na poslovnom tržištu moguće je uspešno koristiti merila koja se odnose na pojedine klijente što značajno doprinosi unapređenju efikasnosti odlučivanja.

Realizovano istraživanje ima ograničeni značaj jer uzorak nije reprezentativan. Mali je broj preduzeća iz različitih oblasti i grana, s obzirom na veličinu, poreklo kapitala, stepenu tržišne orijentisanosti, stepenu inovativnosti i konkurentske pozicioniranosti. Istraživanje je preliminarnog karaktera, a rezultati mogu poslužiti kao dobra osnova za dizajniranje kompleksnih studija: definisanje instrumenata za prikupljanje podataka, izbor jedinica istraživanja, izbor metoda za prikupljanje, obradu i analizu podataka. Ovo istraživanje može biti osnova za buduća istraživanja, u kojima bi na osnovu analiziranih merila usledilo formulisanje specifičnih grupa merila za izabrane sektore i grupe preduzeća.

Dobijeni rezultati vezani za korišćenje i relevantnost merila moraju se pažljivo analizirati. Naime, neka merila, iako su veoma značajna, retko se koriste zbog teškoća u obezbeđivanju potrebnih podataka za njihovo utvrđivanje. Iako su izabrana i ponuđena merila pažljivo birana, neophodno je proširiti listu i istražiti detaljnije svako merilo i mogućnost njegove primene. Jedno od ograničenja koje bi trebalo prevazići u budućim istraživanjima je fokusiranost kako na percepcijama i stavovima menadžera tako i na ispitivanje uticaja merila na efikasnost odlučivanja i ukupne poslovne performanse. S obzirom na zaokrete u poslovnim i marketing modelima, neophodno je listu tradicionalnih merila kompletirati novim koja su okrenuta ka budućnosti sa dugoročnom perspektivom. Nesporno je da su informacije koje se dobijaju vrednovanjem marketing performansi kritične za uspešno strategijsko odlučivanje. Međutim, ako se posmatraju izolovano, ne predstavljaju garanciju uspeha preduzeća kao celine. Stoga bi trebalo da se posmatraju kao integralni segment šire celine i koriste u sprezi sa ostalim mehanizmima, uključujući različite dimenzije i svrhe merenja kao i sisteme nagrađivanja, motivisanja, kao i programe obuke. Merila marketing performansi predstavljaju indikatore putem kojih se sagledava ostvarivanje planiranih marketing i poslovnih ciljeva, kao i definisane marketing i poslovne strategije.

\section{Literatura:}

1. Adler, R. (2011), Performance Management and Organizational Strategy: How to Design Systems that Meet the Needs of Confrontation Strategy Firms, The British Accounting Review, 43, 251-263.

2. Ambler, T. (2000), Marketing Metrics, Business Strategy Review, 11(2), 59.

3. Ambler, T., Kokkimaki,F., Puntoni, S. (2004), Assessing Marketing Performance: Reasons for Metric Selection, Journal of Marketing Management, 20 (3-4): 475-498.
4. Bremser, W. G., Barsky, N. P. (2004), Utilizing the Balanced Scorecard for R\&D Performance Measurement. R\&D Management, 34 (3): 229-238.

5. Chavan, M. (2009), The Balanced Scorecard: a New Challenge. Journal of Management Development, 28 (5): 393-406.

6. Clark, B.H. (1999), Marketing Performance Measures: History and Interrelationship, Journal of Marketing Management, 15, 711-732. 
7. Cocca, P., Alberti, M. (2010), A Framework to Assess Performance Measurement Systems in SMEs, International Journal of Productivity and Performance Management, 59 (2): 186-200.

8. Davis, J. (2005), Measuring Marketing: 103 Key Metrics Every Marketer Needs, Singapore: John Wiley/Sons.

9. Doyle, P. (2007), Value - Based Marketing: Marketing Strategies for Corporate Growth and Shareholder Value, Chicest,: John Wiley

10. Dror, S. (2008), The Balanced Scorecard Versus Quality Award Models as Strategic Frameworks. Total Quality Management, 19 (6): 583-593.

11. Farris, P., Bendle.N. Pfeifer, P., Reibstein, D. (2006), Marketing Metrics: $50+$ Metrics Every Executive Should Master, New Jersey: Wharton School Publishing.

12. Franco-Santos, M., Kennerley, M., Micheli, P., Martinez, V., Mason, S., Marr, B., Gray, D. And Neely, A., (2007), Toward a Definition of a Business Performance Measurement System, International Journal of Operations and Production Management 27 (8):784-801.

13. Garcia-Valderrama, T., Mulero-Mendigorri, E., Revuelta-Bordoy, D. (2008), A Balanced Scorecard Framework for R\&D, European Journal of Innovation Management, 11 (2): 241-281.

14. Garengo, P., A. (2009), A Performance Measurement System for SMEs Taking Part in Quality Award Programmes, Total Quality Management, 20 (1): 91105.

15. Garengo, P., Bernardi, G. (2007), Organizational Capability in SMEs - Performance Measurement as a Key System in Supporting Company Development, International Journal of Productivity and Performance Management, 56 (5/6): 518-532.

16. Gimbert, X., Bisbe, J., Mendoza, X. (2010), The Role of Performance Measurement Systems in Strategy Formulation Processes, Long Range Planning, 43 (4): 477-497.

17. Gonzales-Benito, O., Gonzales-Benito, J. (2005), Cultural vs. Operational Market Orientation and Objective vs. Subjective Performance: Perspective of Production and Operations, Industrial Marketing Management, 34 (8): 797-829.

18. Gupta, S., Lehman, D.R., Stuart, J.A. (2004), Valuing Customers, Journal of Marketing Research, 41(1), 7-18.

19. Gupta, S., Zeithami, V.A. (2006), Customer Metrics and their Impact of Financial Performance, Marketing Science, 25(6), 718-739.

20. Gupta, T.S., Rego, L.L. (2005), Customer Satisfaction, Cash Flow and Shareholder Value, Journal of Marketing, 69(3), 1-18.
21. Hoffman Sampaio, C., Simoes, C., Gatterman Perin, M. \& Almeida, A. (2011), Marketing Metrics: Insights from Brazilian Managers. Industrial Marketing Management, 40 (2011), 8-16.

22. Hooley, G., Greenley, G., Cadogan. J.W., Fahy, J. (2005), The Performance Impact of Marketing Resources, Journal of Business Research, 58 (1): 18-27.

23. Janošević, S., Dženopoljac, V. (2011), Formulisanje strategije istraživanja i razvoja preduzeća pomoću usklađene liste, Ekonomske teme, 49 (2): 197-217.

24. Kanji, G. P., Moura E Sá, P. (2001), Kanji’s Business Scorecard. Total Quality Management, 12 (7): 898905.

25. Kaplan, R. S., Norton, D. P. (1992), The Balanced Scorecard - Measures that Drive Performance. Harvard Business Review, January-February: 71-79.

26. Kaplan, R. S., Norton, D. P. (1996), Using the Balanced Scorecard as a Strategic Management System. Harvard Business Review, January-February: 75-85.

27. Kaplan, R. S., Norton, D. P. (2001), The Strategyfocused Organization: How Balanced Scorecard Companies Thrive in the New Business Environment. Boston: Harvard Business School Press

28. Kaplan, R. S., Norton, D. P. (2004), Strategy Maps Converting Intangible Assets into Tangible Outcomes. Boston: Harvard Business School Press

29. Kaplan, R. S., Norton, D. P. (2008), Mastering the Management System. Harvard Business Review, 86 (January): 63-77.

30. Kaplan, R.S., Norton, D.P. (1996), The Balanced Scorecard: Measures that Drive Performance, Boston, MA: Harvard Business School Press

31. Kornelis, M., Dekimpe, M.G., Leeflang, P.S.H. (2008), Does Competitive Entry Structurally Change Key Marketing Metrics, International Journal of Research in Marketing, 25(3), 173-182.

32. Krstić, B., Sekulić, V. (2007), Upravljanje performansama preduzeća, Ekonomski fakultet Niš

33. La Rocca, Caruana, A., Snehota, I. (2012), Measuring Customer Attractiveness, Industrial Marketing Management (41) 1241-1248.

34. Lages, I.F., Lancastre, A., Lages, C. (2008), The B2B RELPERF Scale and Scorecard: Bringing Relationship Marketing Theory into Business -to-Business Practice, Industrial Marketing Management, 37(6), 686-697.

35. Ling-yee, L. (2011,) Marketing Metrics Usage: Its Predictors and Implications for Customer Relationship Management, Industrial Marketing Management, 40, 139-148. 
36. Maltz, C.A., et. all. (2003) Beyond Balanced Scorecard, Long Range Planning, 36, (2): 187-204.

37. Maričić, B. (2010), Ponašanje potrošača, Centar za izdavačku delatnost Ekonomskog fakulteta u Beogradu

38. McGovern, G.,J.,Court, D., Quelch, J.A., Crawford, B. (2004), Bringing Customers into the Boardroom, Harvard Business Review, 82 (November): 70-80.

39. Micheli, P., Manzoni, J-F. (2010), Startegic Performance Measurement: Benefits, Limitations and Paradoxes, Long Range Planning 43: 465-476.

40. Milisavljević, M. (2010) Strategijski marketing, Centar za izdavačku delatnost ekonomskog fakulteta $\mathrm{u}$ Beogradu

41. Mulhern, F.J. (1999), Customer Profitability Analysis: Measurement, Concentration, and Research Directions, Journal of Interactive Marketing 13(1), 25 40.

42. Narver, J.C., Slater, S.F. (1990), The Effect of Market Orientation on Business Profitability, Journal of Marketing, 54, October, 20-36.

43. Neely, A., Adams, C. (2001), The Performance Prism Perspective, Journal of Cost Management, Vol. 15(1): 7-15.

44. Niven, P. (2002), Balanced Scorecard Step by StepMaximizing Performance and Maintaining Results, John Wiley\&Sons, Inc.

45. Norreklit, H. (2000), The Balance on the Balanced Scorecard - a Critical Analysis of Some of its Assumptions. Management Accounting Research, 11 (1): 65-88.

46. OECD Eurostat (2005), Oslo Manual: Guidelines for Collecting and Interpreting Innovation Data, 3rd ed., Economic Co-operation and Development and Eurostat, Paris

47. O‘Sullivan, D., Abela, A.V. (2007), Marketing Performance Measurement Ability and Firm Performance, Journal of Marketing 71 (2): 79-93.

48. Palmatier, R, W., Dant, R.P., Grewal, D., Evans, K.R. (2006), Factor Influencing the Effectiveness of Relationship Marketing: a Meta-Analysis, Journal of Marketing, 70(4), 136-153.

49. Petersen, J.A., McAlister, L., Reibstein, D.J., Winer, R.S., Kumar, V., Atkinson, G. (2009), Choosing the Right Metrics to Maximize Profitability and Shareholders Value, Journal of Retailing, 85(1), 95111.AILIsr
50. Rayport, J.F., Jaworsky, B.J. (2001), E-Commerce, McGrow Hill International Edition

51. Rust, R.T., Ambler, T., Carpenter, G.S., Kumar, V., Srivastava, R.K. (2004), Measuring Marketing Productivity: Current Knowledge and Future Direction, Journal of Marketing, 68 (4): 76-89.

52. Rust, R.T., Lemon, K.N., Zeithaml, V.A. (2000), Driving Customer Equity: How Customer Lifetime is Reshaping Corporate Strategy, New York, The Free Press

53. Rust, R.T., Lemon, K.N., Zeithaml, V.A. (2004), Return on Marketing: Using Customer Equity to Focus Marketing Strategy, Journal of Marketing, 68 (1): 109-127.

54. Sanches, R., Sanchez, R. (2005), Analysis of Customer Portfolio and Relationship Management Models: Bridging Managerial Dimensions, The Journal of Business and Industrial Marketing, 20(6) 307-316.

55. Seggie, S.H., Cavusgil, E., Phelan, S.E. (2007), Measurement of Return on Marketing Investment: A Conceptual Framework and the Future of Marketing Metrics, Industrial Marketing Management, 36 (6): 834-841.

56. Sheth, J.N., Sisodia, R.S. (2002), Marketing Productivity: Issues and Analysis, Journal of Business Research, 55(5), 349-362.

57. Sousa, S., Aspinwall, E. (2010), Development of a Performance Measurement Framework for SMEs, Total Quality Management, 21 (5): 475-501.

58. Stanković, Lj. (2002), Međuzavisni marketing, Ekonomski fakultet Niš

59. Stanković, Lj. Đukić S. (2004), Integrisani sistemi kontrole marketing odnosa, Ekonomske teme, 41 (3): 15-30.

60. Stanković, Lj. Novićević, B.,Đukić, S. (2012), Designing Corporate Sustainability Performance Measurement System, Facta Universitatis, Series: Economics and organization, Vol. 9 (4), str. 417-427.

61. Lovett, M.J., MacDonald, J.B. (2005), How Does Financial Performance Affect Marketing: Styduing the Marketing-Finance Relatioship from a Dynamic Perspective, Journal of the Academy of Marketing Science, 33(4), 476-485. 
Abstract:

\title{
Improvement an Enterprises Marketing Performance Measurement System
}

\author{
Ljiljana Stanković, Suzana Đukić, Ana Popović
}

Business conditions in which modern enterprises do business are more and more complex. The complexity of the business environment is caused by activities of external and internal factors, which imposes the need for the turn in management focus. One of key turns is related to the need of adaptation and development of new business performance evaluation systems. The evaluation of marketing contribution to business performance is very important however a complex task as well. The marketing theory and practice indicates the need for developing adequate standards and systems for evaluating the efficiency of marketing decisions. The better understanding of marketing standards and ways that managers use is a very important factor that affects the efficiency of strategic decision-making. The paper presents the results of researching the way in which managers perceive and apply marketing performance measures. The data that were received through the field research sample enabled the consideration of the managers' attitudes on practical ways of implementing marketing performance measurement and identifying measures that managers imply as used mostly in business practice.

Keywords: Marketing Capabilities, Performance, Evaluation, Marketing Performance, Measure

\section{Kontakt:}

Ekonomski fakultet Univerziteta u Nišu Trg kralja Aleksandra Ujedinitelja 11, Niš

ljljana.stankovic@eknfak.ni.ac.rs suzana.djukic@eknfak.ni.ac.rs ana.popovic@eknfak.ni.ac.rs 